\title{
Erratum zu: Fragmentierte Teilhabe. Partizipationsgestaltung in stationären erzieherischen Hilfen
}

\section{Erratum zu:}

E. Schierer, Fragmentierte Teilhabe. Partizipationsgestaltung in stationären erzieherischen Hilfen, Perspektiven Sozialwirtschaft und Sozialmanagement, https://doi.org/10.1007/978-3-658-21236-0

In der ursprünglich online veröffentlichten Version des Buches waren drei Kapitel versehentlich aufgeführt, die mit dem Buch nicht in Verbindung standen. Diese wurden nun entfernt. 